\title{
Rates and risk factors for prolonged opioid use after major surgery: population based cohort study
}

\author{
(@) $\mathbb{Q}$ OPEN ACCESS
}

\author{
Hance Clarke assistant professor ${ }^{123}$, Neilesh Soneji lecturer ${ }^{24}$, Dennis T Ko associate professor ${ }^{567}$, \\ Lingsong Yun analyst ${ }^{4}$, Duminda N Wijeysundera assistant professor ${ }^{12578}$
}

${ }^{1}$ Department of Anesthesia and Pain Management, Toronto General Hospital, 200 Elizabeth Street, Eaton North 3 EB 317, Toronto, ON, Canada, M5G 2C4; ${ }^{2}$ Department of Anesthesia, University of Toronto, Canada; ${ }^{3}$ Department of Anesthesia, Sunnybrook Health Sciences Centre, Toronto, Canada; ${ }^{4}$ Department of Anesthesia and Pain Management, Toronto Western Hospital, Canada; ${ }^{5}$ Institute for Clinical Evaluative Sciences, Toronto, Canada; ${ }^{6}$ Division of Cardiology, Schulich Heart Centre, Sunnybrook Health Sciences Centre, University of Toronto, Canada; ${ }^{7}$ Institute of Health Policy Management and Evaluation, University of Toronto, Canada; ${ }^{8} \mathrm{Li}$ Ka Shing Knowledge Institute of St Michael's Hospital, Toronto, Ontario, Canada

\begin{abstract}
Objective To describe rates and risk factors for prolonged postoperative use of opioids in patients who had not previously used opioids and undergoing major elective surgery.

Design Population based retrospective cohort study.

Setting Acute care hospitals in Ontario, Canada, between 1 April 2003 and 31 March 2010.

Participants 39140 opioid naïve patients aged 66 years or older who had major elective surgery, including cardiac, intrathoracic, intra-abdominal, and pelvic procedures.

Main outcome measure Prolonged opioid use after discharge, as defined by ongoing outpatient prescriptions for opioids for more than 90 days after surgery.

Results Of the 39140 patients in the entire cohort, 49.2\% ( $n=19256)$ were discharged from hospital with an opioid prescription, and $3.1 \%$ $(n=1229)$ continued to receive opioids for more than 90 days after surgery. Following risk adjustment with multivariable logistic regression modelling, patient related factors associated with significantly higher risks of prolonged opioid use included younger age, lower household income, specific comorbidities (diabetes, heart failure, pulmonary disease), and use of specific drugs preoperatively (benzodiazepines, selective serotonin reuptake inhibitors, angiotensin converting enzyme inhibitors). The type of surgical procedure was also highly associated with prolonged opioid use. Compared with open radical prostatectomies, both open and minimally invasive thoracic procedures were associated with significantly higher risks (odds ratio $2.58,95 \%$ confidence interval 2.03 to 3.28 and 1.951 .36 to 2.78 , respectively). Conversely, open and minimally invasive major gynaecological procedures were associated
\end{abstract}

with significantly lower risks $(0.73,0.55$ to 0.98 and $0.45,0.33$ to 0.62 , respectively).

Conclusions Approximately $3 \%$ of previously opioid naïve patients continued to use opioids for more than 90 days after major elective surgery. Specific patient and surgical characteristics were associated with the development of prolonged postoperative use of opioids. Our findings can help better inform understanding about the long term risks of opioid treatment for acute postoperative pain and define patient subgroups that warrant interventions to prevent progression to prolonged postoperative opioid use.

\section{Introduction}

Acute postoperative pain and its treatment with opioids are important concerns for the more than 200 million patients who undergo major surgery worldwide every year. ${ }^{1}$ After such surgery, patients often experience moderate to severe pain that interferes with postoperative rehabilitation and discharge from hospital. ${ }^{2}$ Inadequate treatment of acute pain may also contribute to the development of persistent postsurgical pain, ${ }^{3}$ which in turn can have a negative impact on patients' quality of life. ${ }^{45}$

Opioids are key analgesic agents for treating moderate to severe pain after major surgery. ${ }^{6}$ None the less, they have important short term limitations, including side effects and poor efficacy in movement associated pain. Furthermore, some patients develop longer term persistent opioid use, ${ }^{7}$ which negatively impacts on postsurgical quality of life. ${ }^{45}$ Long term use is also associated with increased risks of injury ${ }^{7}$ and cardiac events. ${ }^{8}$ Both the doctors dealing with patients perioperatively and the surgical patients themselves therefore face an important clinical 
challenge-namely, how best to adequately manage acute postoperative pain while tackling patients' understandable concerns about the development of long term opioid use. An important barrier to dealing with this challenge is the current poor understanding of the long term risks associated with opioid treatment for acute postoperative pain. In the setting of low risk day surgery, recent research suggests that patients prescribed opioids within seven days of discharge are almost $50 \%$ more likely to still be receiving an opioid prescription at one year after surgery. ${ }^{7}$ The extent to which these findings in low risk surgery can be generalised to major surgery is, however, unclear. Specifically, postoperative pain control after low risk day surgery may feasibly be managed without opioids, whereas it is unlikely that the moderate to severe postoperative pain associated with major surgery can be managed without resorting to such agents.

In a population based study we describe the rates and associated risk factors of prolonged postoperative use of opioids in patients who had never used opioids undergoing major elective surgery in Ontario, Canada. A better understanding of these factors should greatly aid the decision making of both patients and clinicians.

\section{Methods}

We conducted a retrospective cohort study using several linked population based administrative databases: the discharge abstract database of the Canadian Institute for Health Information (hospital admissions), the Ontario Health Insurance Plan database (doctor service claims), the registered persons database (vital statistics), and the Ontario Drug Benefit database (prescription drugs for outpatients aged $\geq 65$ years). Although these databases lack physiological and laboratory measures (for example, blood pressure, haemoglobin), they have been validated for many outcomes, exposures, and comorbidities. ${ }^{9-11}$ The approximately 13 million residents of Ontario have universal access to doctor and hospital services through a publicly funded healthcare programme. Privacy regulations relating to these databases preclude us from reporting any results for subgroups with fewer than six people.

\section{Assembly of study cohort}

We used the discharge abstract database to identify all Ontario residents who were aged 66 years or older and underwent any one of nine prespecified elective major surgical procedures between 1 April 2003 and 31 March 2010. ${ }^{12}$ An age restriction of 66 years was imposed because data on prescription drugs are only available for those aged 65 years or older, and a preoperative time window was needed for ascertaining previous drug use. The included procedures were isolated coronary artery bypass graft surgery through sternotomy, open (thoracotomy) lung resection surgery, lung resection using video assisted thorascopic surgery, open colon resection surgery, minimally invasive (laparoscopic) colon resection surgery, open radical prostatectomy, minimally invasive (laparoscopic or robot assisted) radical prostatectomy, open total or radical hysterectomy, and minimally invasive (laparoscopic or robot assisted) total or radical hysterectomy. We selected these procedures because they are common and encompass a range of anatomical sites (cardiac, thoracic, abdominal, pelvic) and degrees of surgical invasiveness (open versus minimally invasive approaches). We did not include musculoskeletal procedures such as joint arthroplasty because many patients undergoing such procedures already have considerable pre-existing pain. Procedural information in the discharge abstract database is very accurate. ${ }^{11}$ If patients underwent more than one eligible procedure during the study period, we included only the first procedure.

We used the Ontario Drug Benefit database to exclude those with pre-existing pain disorders before surgery, based on the presence of any outpatient prescriptions for specific analgesic drugs within one year before surgery. These drugs included opioids, gabapentin, tricyclic antidepressants,

serotonin-norepinephrine reuptake inhibitors (for example, duloxetine), anticonvulsants (for example, valproic acid), and topical agents (for example, capsaicin). Prescription data in the Ontario Drug Benefit database are very accurate. ${ }^{14}$ In addition, we used the Ontario Health Insurance Plan database to exclude those who required doctor services for palliative care within one year before or after surgery. The objective of these restrictions was to minimise the inclusion of those who had pre-existing chronic pain disorders or required opioids for end stage cancer.

We characterised participants in the cohort for personal characteristics, socioeconomic status, residence, comorbidities, preoperative drug use, and survival. Personal information (age, sex) was obtained from the registered persons database. We estimated patients' socioeconomic status based on the median income of their neighbourhood in the Canadian census, and characterised their residence as rural versus urban using Statistics Canada definitions. ${ }^{15}$ To identify patients with diabetes or hypertension we used validated algorithms. ${ }^{10}$ We used the Ontario Health Insurance Plan database to identify patients who required dialysis before surgery. Using the discharge abstract database, we used previously described methods to identify other comorbidities based on ICD-10 codes (international classification of diseases, 10th revision) from admissions to hospital within three years before surgery: coronary artery disease, heart failure, cerebrovascular disease, peripheral vascular disease, pulmonary disease, chronic renal insufficiency, and malignancy. ${ }^{16}$ We used the Ontario Drug Benefit database to ascertain the preoperative use of drugs that may be related (selective serotonin reuptake inhibitors (SSRIs), benzodiazepines) and unrelated ( $\beta$ blockers, angiotensin converting enzyme (ACE) inhibitors, angiotensin receptor blockers, statins) to postoperative opioid use. To identify outpatient prescriptions for these drugs, we used a 90 day time window before the index surgery. We ascertained postoperative survival using the discharge abstract database (in-hospital mortality) and registered persons database (mortality out of hospital).

\section{Postoperative opioid use}

The Ontario Drug Benefit database was used to ascertain opioid use after hospital discharge. These opioids included codeine, morphine, oxycodone, hydromorphone, meperidine,

oxymorphone, methadone, and transdermal fentanyl. We also characterised these drugs by whether they were sustained release formulations. Early post-discharge opioid use was defined as one or more prescriptions for opioids within 1 to 90 days after surgery. Prolonged opioid use after hospital discharge was defined as one or more opioid prescriptions within 1 to 90 days after surgery along with one or more prescriptions for opioids within 91 to 180 days after surgery. This 90 day minimum interval for defining prolonged opioid use is more conservative than the 60 day interval used by the International Association for the Study of Pain to define persistent postsurgical pain, ${ }^{17}$ which has been criticised as being too short. ${ }^{18}$ 


\section{Statistical analysis}

All analyses were performed using SAS version 9.2 (SAS Institute, Cary, NC), and we used a two tailed P value of less than 0.05 to define statistical significance. We initially used descriptive statistics to characterise the cohort for patterns of post-discharge opioid use. To compare the characteristics of patients who did or did not exhibit prolonged opioid use after discharge we also used bivariate tests (two sample $t$ test, Mann-Whitney U test, $\chi^{2}$ test, Fisher exact test).

We used multivariable logistic regression modelling to determine the adjusted association of prolonged opioid use after discharge ( $\geq 1$ prescriptions within 1-90 days after surgery along with $\geq 1$ prescriptions within 91-180 days after surgery) with age (categorised as 66-75, 76-85, and $\geq 86$ years), sex, surgery, fifth of neighbourhood income, rural residence, comorbidities (coronary artery disease, heart failure, cerebrovascular disease, peripheral vascular disease, diabetes, hypertension, pulmonary disease, chronic renal insufficiency, malignancy), and preoperative drug use ( $\beta$ blockers, ACE inhibitors, angiotensin receptor blockers, statins, benzodiazepines, SSRIs). All predictor variables were included simultaneously in the multivariable regression model. In the primary analysis, we included all participants in the cohort regardless of whether they survived up to 180 days after surgery. In a sensitivity analysis, we repeated the analyses after restricting the cohort to only those who survived at least 180 days after surgery.

\section{Results}

The cohort consisted of 39140 patients who had not previously used opioids and underwent major elective surgery. Of these, $49.2 \%$ ( $n=19256)$ used opioids in the early post-discharge period, and $3.1 \%(n=1229)$ used opioids for a prolonged period after discharge. Table $1 \Downarrow$ presents the patterns of post-discharge opioid use across the different surgical procedures. The highest risk of prolonged opioid use was after open $(8.5 \%)$ or minimally invasive $(6.3 \%)$ intrathoracic procedures. Postoperative survival was $98.3 \%(n=38492)$ at hospital discharge, $97.4 \%(n=38124)$ at 90 days after surgery, and $96.7 \%(n=37857)$ at 180 days after surgery.

Table $2 \Downarrow$ presents the proportion of participants with prolonged opioid use after discharge, according to their perioperative characteristics. Supplementary table 1 presents the bivariate comparisons of those who did or did not develop prolonged opioid use. In unadjusted analyses, those who developed prolonged opioid use were more likely to reside in lower income neighbourhoods and to have specific preoperative comorbidities or to use specific drugs (table $3 \Downarrow$ ). Following multivariable risk adjustment, several patient characteristics had statistically significant associations with prolonged opioid use (table 3 ). They included younger age, lower fifth of neighbourhood income, specific comorbidities (diabetes, heart failure, pulmonary disease), and use of specific drugs preoperatively (benzodiazepines, SSRIs, ACE inhibitors). Surgical procedure was also an important determinant of prolonged opioid use (table 3). Compared with open radical prostatectomies, open and minimally invasive intrathoracic procedures were associated with higher risks of prolonged opioid use (odds ratio $2.58,95 \%$ confidence interval 2.03 to 3.28 and $1.95,1.36$ to 2.78 , respectively). Conversely, hysterectomies (open and minimally invasive) and minimally invasive radical prostatectomies were associated with lower risks of prolonged opioid use. Our results were unchanged when the analyses were repeated among patients who survived until 180 days after surgery (see supplementary table 2).

\section{Discussion}

Although almost $50 \%$ of patients who had never previously used opioids were discharged from hospital with an opioid prescription after major elective surgery, $3.1 \%$ continued to be prescribed opioids for more than three months after surgery. We identified several factors associated with development of prolonged opioid use, especially surgery type, with open intrathoracic procedures having a 2.5 -fold higher risk and minimally invasive intrathoracic procedures having a 1.95-fold higher risk. Other risk factors for prolonged opioid use included younger age, lower socioeconomic status, diabetes, heart failure, pulmonary disease, and use of specific drugs preoperatively (benzodiazepines, selective serotonin reuptake inhibitors (SSRIs), ACE (angiotensin converting enzyme) inhibitors).

A key finding of our study is that only 1 in 30 patients exposed to opioids after major surgery continued to use them for more than three months. Given the types of surgical procedures included in this study, it can be reasonably assumed that all of these patients had been exposed to opioids during their in-hospital stay. The $3.1 \%$ risk of prolonged opioid use is relatively low; indeed, it is lower than the proportion of patients reported to be using opioids at one year after low risk surgery $(7.7 \%)^{7}$ The discrepancy in reported risks is possibly explained by differing methodologies. Specifically, long term opioid use was defined in the previous study as any opioid prescription within 305 to 425 days after surgery, regardless of whether opioids were prescribed during the intervening postoperative period. Indeed, $90 \%$ of such long term users had not been prescribed opioids immediately after surgery. In contrast, prolonged opioid use was more strictly defined in our present study as any opioid prescription within 1 to 90 days after surgery, and any opioid prescription within 91 to 180 days after surgery. Patients can therefore be reassured that when people receive opioids appropriately to treat acute pain after major surgery, the majority do not experience prolonged use. Our findings therefore help inform patients' and clinicians' understanding of the risks of prolonged opioid use after major surgery, especially since patients' understandable fears about opioid dependence may be an important barrier to achieving adequate acute postsurgical pain relief.

None the less, given the millions of major surgical procedures performed worldwide every year, ${ }^{1} 3.1 \%$ does represent a large absolute number of patients who continue to use opioids for more than three months after surgery. This relatively low individual risk of $3.1 \%$ thus still represents a substantial overall public health concern at the population level. It is therefore critical that we elucidate the risk factors, as well as underlying mechanisms, for the development of prolonged postoperative opioid use. Our study identified several such risk factors, including surgical procedure, younger age, lower socioeconomic status, and specific comorbidities or use of specific drugs preoperatively. The underlying mechanisms that might explain the association of these risk factors with prolonged opioid use include development of persistent postsurgical pain, non-pain related factors driving opioid prescription (that is, doctors' prescription practises, geographical location, addiction), and the presence of pre-existing unmet needs for pain before surgery. The development of persistent postsurgical pain may explain the association of prolonged postoperative opioid use with thoracic surgical procedures, younger age, and drugs used to treat anxiety or depression (that is, benzodiazepines, SSRIs). Approximately $40-80 \%$ of patients with a thoracotomy incision develop post-thoracotomy pain syndrome, which in turn impairs activities of daily living, disrupts sleep, ${ }^{19} 20$ and leads to long 
term analgesic use. ${ }^{20}{ }^{21}$ In more than $50 \%$ of cases, this pain is neuropathic in origin, ${ }^{22}{ }^{23}$ presumably due to nerve injury or compression during the surgical procedure. ${ }^{23}{ }^{24}$ Importantly, such neuropathic pain is poorly responsive to treatment with opioids alone. Such affected patients should instead receive first line drugs for neuropathic pain (for example, anticonvulsants, tricyclic antidepressants, serotonin-norepinephrine reuptake inhibitors), ${ }^{25}$ either alone or combination with opioids.

Previous work has also identified younger biological age as a predictor of subsequent persistent postsurgical pain, which may explain in part the association of younger age with prolonged opioid use in our study. ${ }^{26}{ }^{27}$ Conversely, the protective characteristic of advanced age for development of persistent postsurgical pain has also been identified in preclinical ${ }^{28}$ and clinical studies. ${ }^{29}$ Preoperative fear and anxiety have been shown to be correlated with acute postoperative pain, acute postoperative analgesic consumption, ${ }^{30}$ and risks of subsequent persistent postsurgical pain. ${ }^{31}{ }^{32}$ After surgery, depression, psychological vulnerability, and stress are also correlated with the presence of persistent postsurgical pain..$^{33}$ Thus, pre-existing anxiety and depression may be underlying mechanisms explaining the association of prolonged opioid use with preoperative use of benzodiazepine and SSRIs.

Several factors unrelated to pain, such as doctors' prescription practises, might also have played a role in the development of prolonged postoperative opioid use in our cohort. For example, we found that patients with heart failure or receiving ACE inhibitors had an increased risk of continuing opioids for more than three months after major surgery. This increased risk might be explained, in part, by doctors' concerns about precipitating decompensated heart failure as a result of non-steroidal anti-inflammatory drugs being administered to patients with known heart failure, thereby leading to a preferential use of opioids for managing postoperative pain. In addition, we found that residence in lower income neighbourhoods was a predictor of prolonged postoperative opioid use, with evidence of a clear dose-response relation between decreasing neighbourhood income and increasing risks for opioid use (table 3). Non-pain related factors have explained this relation, such as unmeasured patient level characteristics, doctors' prescribing practises in lower income neighbourhoods, or greater reluctance among patients on a lower income to question their doctors about the appropriateness of prolonged opioid treatment. Our findings on markers of socioeconomic status are consistent with previous research examining opioid utilisation for non-cancer pain among recipients of social assistance. ${ }^{34}$ This research found that socioeconomically disadvantaged patients used more opioid drugs more often and at higher prescribed doses. The development of opioid dependence or addiction, although not captured by our data sources, may have also accounted for the development of prolonged opioid use in some patients in our cohort.

Although we tried to exclude people with pre-existing pain disorders from our study cohort, it is possible that some participants still had unmet pain management needs before surgery. Such people may have found that opioids prescribed for acute postoperative pain also helped manage chronic pre-existing pain conditions (for example, osteoarthritis) that were undertreated before surgery. These patients may in turn continue to use opioids persistently after surgery to manage these pre-existing chronic pain conditions, as opposed to pain directly related to surgery. The contribution of this underlying mechanism is supported by the increased risk of prolonged postoperative opioid use in patients with preoperative comorbidities that are known to be associated with unrelieved chronic pain conditions. For example, patients with heart failure ${ }^{35-37}$ or with chronic obstructive pulmonary disease ${ }^{38}$ have been shown to have unrelieved pain conditions. In our present study, these same patients also had higher risks of developing prolonged postoperative opioid use.

\section{Implications for future research}

Our results help facilitate the appropriate design of future studies of interventions to help mitigate risks of prolonged opioid use. Specifically, such studies should focus on high risk patients, especially since the majority of patients who had not used opioids before major surgery in this study did not develop persistent opioid requirements. The risk factors identified in our present study should facilitate identification of these high risk subgroups for participation in such trials. Future research should also include prospective studies with detailed follow-up to confirm our findings and to better understand why people with these risk factors continue to use opioids. Understanding the mechanisms underlying the development of prolonged opioid use is key to developing appropriate interventions to decrease opioid use. For example, interventions that focus exclusively on restricting access to opioids for patients after surgery would not be appropriate if the predominant causal mechanism is development of persistent postsurgical pain. In such a scenario, research into interventions should possibly focus on intervening in high risk patients before or immediately after surgery to help mitigate development of persistent postsurgical pain, potentially by minimising the deleterious immediate and long term effects of noxious perioperative afferent input. ${ }^{39}$

\section{Limitations of this study}

Our study should be interpreted cautiously in light of its limitations. Firstly, our data sources lacked important clinical details such as in-hospital drug use, reasons for opioid prescriptions, and some complications, such as persistent postsurgical pain. We therefore cannot determine whether prolonged postoperative opioid use in individual patients was reflective of persistent postsurgical pain, physiological opioid dependence, addiction, or even opioid diversion. Secondly, our cohort only included patients aged 66 years or older, by virtue of limitations of prescription data available in our administrative databases. Thus, the generalisability of our findings to younger populations is uncertain. Thirdly, patients taking opioids before surgery were excluded from the current study; hence we are unable to extrapolate our findings to opioid dependent patients presenting for major surgery. Fourthly, as our study was observational, it does not prove that all identified associations represented causal relations. Future research should therefore include similar large retrospective studies to assess the replicability of our findings, prospective cohort studies to capture detailed information on pathophysiological mechanisms underlying prolonged postoperative opioid use, and randomised controlled trials to evaluate promising interventions that act on these presumed underlying mechanisms to help prevent prolonged postoperative opioid use.

\section{Conclusions}

Within the context of the growing concern of an addiction crisis resulting from doctor prescribed drugs,${ }^{40}$ major surgery remains a common healthcare scenario where some degree of opioid use is largely unavoidable. This population based multicentre study provides reassurance to both the doctors dealing with patients preoperatively and the patients themselves about the potential risks of opioid use after major surgery. Indeed, our findings 
indicate that a simple global restriction of opioids for every patient undergoing major surgery would simply not be appropriate. In addition, we identified several important risk factors for prolonged postoperative opioid use.

Future research should be focused on high risk patients with these predictive factors, both to delineate mechanisms for development of prolonged opioid use and to evaluate preventive interventions. Such research is critical if doctors are to ensure that low risk surgical patients continue to have access to postoperative opioids for effective relief of acute pain, while high risk patients receive the targeted effective interventions needed to mitigate risk of prolonged opioid use.

Contributors: HC, NS, DTK, and DNW contributed to the conception and design of the study. DTK, LY, and DNW contributed to the analysis, and all authors contributed to its interpretation. $\mathrm{HC}$ and DNW drafted the article; all authors revised it critically for important intellectual content and approved the final version submitted for publication. $\mathrm{HC}$ is the guarantor.

Funding: $\mathrm{HC}$ and DNW are supported by Merit Awards from the Department of Anesthesia at the University of Toronto. HC is supported by the STAGE Training Program in Genetic Epidemiology from the Canadian Institutes of Health Research. DNW is supported by a Clinician-Scientist award from the Canadian Institutes of Health Research. DTK is supported by a Clinician-Scientist award from the Heart and Stroke Foundation of Ontario. This study was supported in part by the Institute for Clinical Evaluative Sciences, which is itself supported in part by the Ontario Ministry of Health and Long-Term Care. The study sponsor had no role in the design and conduct of the study; collection, management, analysis, and interpretation of the data; or preparation, review, and approval of the manuscript. The opinions, results, and conclusions are those of the authors, and no endorsement by the Ontario Ministry of Health and Long-Term Care or the Institute for Clinical Evaluative Sciences is intended or should be inferred.

Competing interests: All authors have completed the ICMJE uniform disclosure form at http://www.icmje.org/coi_disclosure.pdf (available on request from the corresponding author) and declare: no support from any company for the submitted work; and no non-financial interests that may be relevant to the submitted work. $\mathrm{HC}$ has the following relationships with companies that might have an interest in the submitted work, which may be perceived as a competing interest: an externally peer reviewed grant from Pfizer Canada to evaluate perioperative pregabalin for pain management after hip replacement surgery. Otherwise, the authors have no financial relationships with any organisations that might have an interest in the submitted work in the previous three years.

Ethical approval: This study was approved by Sunnybrook Health Sciences Centre.

Data sharing: No additional data available.

Transparency: The corresponding author affirms that this manuscript is an honest, accurate, and transparent account of the study being reported; that no important aspects of the study have been omitted; and that any discrepancies from the study as planned (and, if relevant, registered) have been explained. The corresponding author is the study guarantor.

1 Weiser TG, Regenbogen SE, Thompson KD, Haynes AB, Lipsitz SR, Berry WR, et al. An estimation of the global volume of surgery: a modelling strategy based on available data. Lancet 2008:372:139-44.

2 Dolin SJ, Cashman JN, Bland JM. Effectiveness of acute postoperative pain management: I. Evidence from published data. Br J Anaesth 2002;89:409-23.

3 Katz J, Seltzer Z. Transition from acute to chronic postsurgical pain: risk factors and protective factors. Expert Rev Neurother 2009;9:723-44.

4 Kinney MAO, Hooten WM, Cassivi SD, Allen MS, Passe MA, Hanson AC, et al. Chronic postthoracotomy pain and health-related quality of life. Ann Thorac Surg 2012:93:1242-7.

5 Mongardon N, Pinton-Gonnet C, Szekely B, Michel-Cherqui M, Dreyfus J-F, Fischler M. Assessment of chronic pain after thoracotomy: a 1-year prevalence study. Clin J Pain 2011;27:677-81.
6 Strassels SA, McNicol E, Suleman R. Postoperative pain management: a practical review, part 2. Am J Health Syst Pharm 2005;62:2019-25.

7 Alam A, Gomes T, Zheng H, Mamdani MM, Juurlink DN, Bell CM. Long-term analgesic use after low-risk surgery: a retrospective cohort study. Arch Intern Med 2012;172:425-30. 8 Solomon DH, Rassen JA, Glynn RJ, Garneau K, Levin R, Lee J, et al. The comparative safety of opioids for nonmalignant pain in older adults. Arch Intern Med 2010;170:1979-86.

9 Austin PC, Daly PA, Tu JV. A multicenter study of the coding accuracy of hospital discharge administrative data for patients admitted to cardiac care units in Ontario. Am Heart $J$ 2002;144:290-6.

10 Hux JE, Ivis F, Flintoft V, Bica A. Diabetes in Ontario: determination of prevalence and incidence using a validated administrative data algorithm. Diabetes Care 2002;25:512-6.

11 Juurlink D, Croxford R, Chong A, Austin PC, Tu JV, Laupacis A. Canadian Institute for Health Information Discharge Abstract Database: a validation study. ICES Investigative Report. Institute for Clinical Evaluative Sciences, 2006.

12 Technical supplement: health care in Canada 2005. Canadian Institute for Health Information, 2005.

13 Fleisher LA, Beckman JA, Brown KA, Calkins H, Chaikof EL, Fleischmann KE, et al. ACCF/AHA focused update on perioperative beta blockade incorporated into the ACC/AHA 2007 Guidelines on perioperative cardiovascular evaluation and care for noncardiac surgery: a report of the American College Of Cardiology Foundation/American Heart Association Task Force on Practice Guidelines. Circulation 2009;120:e169-276.

14 Levy AR, O'Brien BJ, Sellors C, Grootendorst P, Willison D. Coding accuracy of administrative drug claims in the Ontario Drug Benefit database. Can J Clin Pharmacol 2003;10:67-71.

15 Du Plessis V, Beshri R, Bollman RD, Clemeson H. Definitions of "rural." Agriculture and Rural Working Paper Series, No 61. Statistics Canada, Agriculture Division, 2002.

16 Quan H, Sundararajan V, Halfon P, Fong A, Burnand B, Luthi JC, et al. Coding algorithms for defining comorbidities in ICD-9-CM and ICD-10 administrative data. Med Care 2005;43:1130-9.

17 Macrae WA, Davies HTO. Chronic postsurgical pain. In: Crombie LK, Linton S, Croft P, Von Korff M, LeResche L, eds. Epidemiology of pain. IASP Press, 1999:125-42.

18 Kehlet H, Rathmell JP. Persistent postsurgical pain: the path forward through better design of clinical studies. Anesthesiology 2010;112:514-5.

19 Tiippana E, Nilsson E, Kalso E. Post-thoracotomy pain after thoracic epidural analgesia: a prospective follow-up study. Acta Anaesthesiol Scand 2003;47:433-8.

20 Wildgaard K, Ravn J, Nikolajsen L, Jakobsen E, Jensen TS, Kehlet H. Consequences of persistent pain after lung cancer surgery: a nationwide questionnaire study. Acta Anaesthesiol Scand 2011;55:60-8.

21 Steegers MAH, Snik DM, Verhagen AF, van der Drift MA, Wilder-Smith OHG. Only half of the chronic pain after thoracic surgery shows a neuropathic component. J Pain 2008;9:955-61.

22 Maguire MF, Ravenscroft A, Beggs D, Duffy JP. A questionnaire study investigating the prevalence of the neuropathic component of chronic pain after thoracic surgery. Eur $J$ Cardiothorac Surg 2006;29:800-5.

23 Duale C, Guastella V, Morand D, Cardot JM, Aublet-Cuvelier B, Mulliez A, et al. Characteristics of the neuropathy induced by thoracotomy: a 4-month follow-up study with psychophysical examination. Clin J Pain 2011;27:471-80.

24 Johansen A, Romundstad L, Nielsen CS, Schirmer H, Stubhaug A. Persistent postsurgical pain in a general population: prevalence and predictors in the Tromso study. Pain 2012;153:1390-6.

25 Dworkin RH, O'Connor AB, Backonja M, Farrar JT, Finnerup NB, Jensen TS, et al. Pharmacologic management of neuropathic pain: evidence-based recommendations. Pain 2007;132:237-51

26 Kalkman CJ, Visser K, Moen J, Bonsel GJ, Grobbee DE, Moons KG. Preoperative prediction of severe postoperative pain. Pain 2003;105:415-23.

27 Poleshuck EL, Katz J, Andrus CH, Hogan LA, Jung BF, Kulick DI, et al. Risk factors for chronic pain following breast cancer surgery: a prospective study. J Pain 2006;7:626-34

28 Pickering G, Jourdan D, Millecamps M, Chapuy E, Alliot J, Eschalier A. Age-related impact of neuropathic pain on animal behaviour. Eur J Pain 2006;10:749-55.

29 Gartner R, Jensen MB, Nielsen J, Ewertz M, Kroman N, Kehlet H. Prevalence of and factors associated with persistent pain following breast cancer surgery. JAMA 2009;302:1985-92.

30 Katz J, Buis T, Cohen L. Locked out and still knocking: predictors of excessive demands for postoperative intravenous patient-controlled analgesia. Can J Anaesth 2008;55:88-99.

31 Forsythe ME, Dunbar MJ, Hennigar AW, Sullivan MJ, Gross M. Prospective relation between catastrophizing and residual pain following knee arthroplasty: two-year follow-up. Pain Res Manag 2008;13:335-41.

32 Sullivan M, Tanzer M, Stanish W, Fallaha M, Keefe FJ, Simmonds M, et al. Psychological determinants of problematic outcomes following total knee arthroplasty. Pain 2009;143:123-9.

33 Hinrichs-Rocker A, Schulz K, Jarvinen I, Lefering R, Simanski C, Neugebauer EA. Psychosocial predictors and correlates for chronic post-surgical pain (CPSP)—a systematic review. Eur J Pain 2009;13:719-30.

34 Gomes T, Juurlink DN, Dhalla IA, Mailis-Gagnon A, Paterson JM, Mamdani MM. Trends in opioid use and dosing among socio-economically disadvantaged patients. Open Med 2011;5:e13-22.

35 Rustoen T, Stubhaug A, Eidsmo I, Westheim A, Paul SM, Miaskowski C. Pain and quality of life in hospitalized patients with heart failure. J Pain Symptom Manage 2008;36:497-504.

36 Goebel JR, Doering LV, Shugarman LR, Asch SM, Sherbourne CD, Lanto AB, et al. Hear failure: the hidden problem of pain. J Pain Symptom Manage 2009;38:698-707.

37 Udeoji DU, Shah AB, Bharadwaj P, Katsiyiannis P, Schwarz ER. Evaluation of the prevalence and severity of pain in patients with stable chronic heart failure. World $J$ Cardiol 2012;4:250-5.

38 Lohne V, Heer HC, Andersen M, Miaskowski C, Kongerud J, Rustoen T. Qualitative study of pain of patients with chronic obstructive pulmonary disease. Heart Lung 2010;39:226-34

39 Katz J, Clarke H, Seltzer Z. Review article: preventive analgesia: quo vadimus? Anesth Analg 2011;113:1242-53.

40 Kluger J. The new drug crisis; addiction by prescription. Time 2010;176:46-9.

Accepted: 23 January 2014

Cite this as: BMJ 2014;348:g1251 


\section{What is already known on this topic}

Although opioids are effective for acute postoperative pain, patients requiring major surgery may be concerned about developing prolonged use from perioperative use of opioids

The risk of developing prolonged postoperative opioid use after major surgery is unclear

\section{What this study adds}

Approximately $3.1 \%$ of patients who had not used opioids previously continued to use them for more than 90 days after major elective surgery

Although 3.1\% risk is low at an individual patient's level, it represents an important public health concern because millions of patients undergo major surgery every year

Factors associated with the development of prolonged postoperative opioid use include younger age, lower income, specific comorbidities, use of specific preoperative drugs, and thoracic surgical procedures

This is an Open Access article distributed in accordance with the Creative Commons Attribution Non Commercial (CC BY-NC 3.0) license, which permits others to distribute, remix, adapt, build upon this work non-commercially, and license their derivative works on different terms, provided the original work is properly cited and the use is non-commercial. See: http://creativecommons.org/licenses/by-nc/3.0/. 


\section{Tables}

Table 1/ Patterns of post-discharge opioid use across different surgical procedures. Values are proportions (\%) with exact $95 \%$ binomial confidence intervals

\begin{tabular}{|c|c|c|c|}
\hline \multirow[b]{2}{*}{ Procedures } & \multirow[b]{2}{*}{$\begin{array}{c}\text { No of participants }(n=39 \\
140)\end{array}$} & \multicolumn{2}{|c|}{ Duration of opioid use } \\
\hline & & Early post-discharge ${ }^{\star} \%(95 \% \mathrm{Cl})$ & $\begin{array}{l}\text { Prolonged post-discharge } \% \text { \% }(95 \% \\
\mathrm{Cl})\end{array}$ \\
\hline \multicolumn{4}{|l|}{ Urological surgerył: } \\
\hline $\begin{array}{l}\text { Radical prostatectomy (open and minimally } \\
\text { invasive) }\end{array}$ & 5193 & $65.2(63.9$ to 66.5$)$ & 2.8 (2.4 to 3.2 ) \\
\hline Coronary artery bypass graft via sternotomy & 9488 & 53.5 (52.4 to 54.5$)$ & $3.3(2.9$ to 3.6$)$ \\
\hline \multicolumn{4}{|l|}{ Intrathoracic surgery: } \\
\hline Minimally invasive lung resection & 720 & $65.7(62.1$ to 69.2$)$ & $6.3(4.6$ to 8.3$)$ \\
\hline Open lung resection & 2423 & 72.4 (70.6 to 74.2$)$ & 8.5 (7.4 to 9.6$)$ \\
\hline \multicolumn{4}{|l|}{ Intra-abdominal surgery: } \\
\hline Minimally invasive colorectal surgery & 3202 & 44.1 (42.3 to 45.9$)$ & $3.2(2.6$ to 3.9$)$ \\
\hline Open colorectal surgery & 8642 & 38.0 (37.0 to 39.1$)$ & $2.8(2.4$ to 3.1$)$ \\
\hline \multicolumn{4}{|l|}{ Gynaecological surgery: } \\
\hline Minimally invasive hysterectomy & 5287 & 35.7 (34.4 to 37.0$)$ & $1.5(1.2$ to 1.8$)$ \\
\hline Open hysterectomy & 4185 & 47.3 (45.7 to 48.8 ) & 2.5 (2.1 to 3.0$)$ \\
\hline
\end{tabular}

${ }^{*} \geq 1$ prescriptions for opioids within 1-90 days after surgery.

$\dagger \geq 1$ prescriptions for opioids within 1-90 days after surgery, along with $\geq 1$ prescriptions for opioids within 91-180 days after surgery.

$\ddagger$ Subgroup specific results for open versus minimally invasive prostatectomy not reported owing to privacy regulations on reporting of small numbers of people within subgroups. 
Table 2| Proportions of patients with prolonged post-discharge opioid use, according to perioperative characteristics

\section{Characteristics}

No of participants $(n=39140)$

No (\%) with prolonged post-discharge opioid use

Age group (years):

\begin{tabular}{|c|c|c|}
\hline $66-75$ & 26509 & $851(3.2)$ \\
\hline $76-85$ & 11398 & $353(3.1)$ \\
\hline$\geq 86$ & 1233 & $25(2.0)$ \\
\hline Women & 18753 & $554(3.0)$ \\
\hline \multicolumn{3}{|l|}{ Neighbourhood income fifth: } \\
\hline First (lowest) & 6741 & $248(3.7)$ \\
\hline Second & 8009 & $283(3.5)$ \\
\hline Third & 7776 & $250(3.2)$ \\
\hline Fourth & 8170 & $222(2.7)$ \\
\hline Fifth (highest) & 8444 & $226(2.7)$ \\
\hline Rural residence & 6130 & $187(3.1)$ \\
\hline \multicolumn{3}{|l|}{ Surgical procedure: } \\
\hline Coronary artery bypass graft & 9488 & $310(3.3)$ \\
\hline Minimally invasive lung resection surgery & 720 & $45(6.2)$ \\
\hline Open lung resection surgery & 2423 & $205(8.5)$ \\
\hline Minimally invasive colorectal surgery & 3202 & $102(3.2)$ \\
\hline Open colorectal surgery & 8642 & $238(2.8)$ \\
\hline Minimally invasive hysterectomy & 5287 & $78(1.5)$ \\
\hline Open hysterectomy & 4185 & $105(2.5)$ \\
\hline Prostatectomy (open and minimally invasive) ${ }^{*}$ & 5193 & $146(2.8)$ \\
\hline \multicolumn{3}{|l|}{ Comorbid disease: } \\
\hline Coronary artery disease & 11735 & $400(3.4)$ \\
\hline Heart failure & 1340 & $64(4.8)$ \\
\hline Cerebrovascular disease & 673 & $27(4.0)$ \\
\hline Peripheral vascular disease & 751 & $26(3.5)$ \\
\hline Diabetes & 10156 & $376(3.7)$ \\
\hline Hypertension & 28360 & $934(3.3)$ \\
\hline Pulmonary disease & 1051 & $70(6.7)$ \\
\hline Renal disease & 1190 & $45(3.8)$ \\
\hline \multicolumn{3}{|l|}{ Malignancy: } \\
\hline Primary & 9930 & $341(3.4)$ \\
\hline Metastatic & 354 & $20(5.6)$ \\
\hline \multicolumn{3}{|l|}{ Preoperative drugs: } \\
\hline Benzodiazepines & 4518 & $188(4.2)$ \\
\hline SSRIs & 1556 & $73(4.7)$ \\
\hline$\beta$ blockers & 12628 & $434(3.4)$ \\
\hline Statins & 16565 & $566(3.4)$ \\
\hline ACE inhibitors & 12568 & $473(3.8)$ \\
\hline Angiotensin receptor blockers & 5425 & $178(3.3)$ \\
\hline
\end{tabular}

$A C E=$ angiotensin converting enzyme; SSRIs=selective serotonin reuptake inhibitors.

*Subgroup specific results for open versus minimally invasive prostatectomy are not presented owing to privacy regulations on reporting of small numbers of people within subgroups. 


\begin{tabular}{|c|c|c|c|c|}
\hline \multirow[b]{2}{*}{ Factors } & \multicolumn{2}{|c|}{ Unadjusted comparison } & \multicolumn{2}{|c|}{ Adjusted comparison } \\
\hline & Odds ratio $(95 \% \mathrm{Cl})$ & $P$ value & Odd ratio $(95 \% \mathrm{Cl})$ & $P$ value \\
\hline \multicolumn{5}{|l|}{ Personal characteristics } \\
\hline Women & 0.89 (0.79 to 1.00$)$ & 0.04 & 1.10 (0.96 to 1.27$)$ & 0.19 \\
\hline \multicolumn{5}{|l|}{ Age groups (years): } \\
\hline $66-75$ & 1.60 (1.07 to 2.40$)$ & \multirow[t]{3}{*}{0.06} & 1.63 (1.08 to 2.46$)$ & \multirow[t]{3}{*}{0.03} \\
\hline $76-85$ & 1.54 (1.03 to 2.33$)$ & & 1.47 (0.97 to 2.22$)$ & \\
\hline$\geq 86$ & Reference & & Reference & \\
\hline \multicolumn{5}{|l|}{ Income fifth: } \\
\hline 1 (lowest) & Reference & \multirow[t]{5}{*}{$<0.001$} & Reference & \multirow[t]{5}{*}{0.005} \\
\hline 2 & $0.96(0.81$ to 1.14$)$ & & $0.98(0.82$ to 1.16$)$ & \\
\hline 3 & $0.87(0.73$ to 1.04$)$ & & $0.90(0.75$ to 1.07$)$ & \\
\hline 4 & 0.73 (0.61 to 0.88$)$ & & $0.76(0.63$ to 0.92$)$ & \\
\hline 5 (highest) & $0.72(0.60$ to 0.87$)$ & & 0.77 (0.64 to 0.93$)$ & \\
\hline \multicolumn{5}{|l|}{ Rural residence: } \\
\hline Urban & Reference & \multirow[t]{2}{*}{0.66} & Reference & \multirow[t]{2}{*}{0.79} \\
\hline Rural & $0.97(0.83$ to 1.13$)$ & & $0.98(0.83$ to 1.15$)$ & \\
\hline Surgical procedures & & $<0.001$ & & $<0.001$ \\
\hline \multicolumn{5}{|l|}{ Radical prostatectomy: } \\
\hline Open prostatectomy & Reference & & Reference & \\
\hline Minimally invasive prostatectomy & $0.36(0.13$ to 0.98$)$ & & $0.37(0.14$ to 1.01$)$ & \\
\hline CABG via sternotomy & $1.11(0.91$ to 1.36$)$ & & $0.95(0.71$ to 1.29$)$ & \\
\hline \multicolumn{5}{|l|}{ Intrathoracic surgery: } \\
\hline Open lung resection & 3.05 (2.45 to 3.80$)$ & & 2.58 (2.03 to 3.28$)$ & \\
\hline Minimally invasive lung resection & $2.20(1.56$ to 3.10$)$ & & 1.95 (1.36 to 2.78$)$ & \\
\hline \multicolumn{5}{|l|}{ Intra-abdominal surgery: } \\
\hline Open colorectal surgery & 0.93 (0.76 to 1.15$)$ & & $0.84(0.67$ to 1.07$)$ & \\
\hline Minimally invasive colorectal surgery & $1.09(0.84$ to 1.40$)$ & & $1.00(0.76$ to 1.32$)$ & \\
\hline \multicolumn{5}{|l|}{ Total hysterectomy: } \\
\hline Open hysterectomy & 0.85 (0.66 to 1.10$)$ & & 0.73 (0.55 to 0.98$)$ & \\
\hline Minimally invasive hysterectomy & 0.49 (0.37 to 0.65$)$ & & 0.45 (0.33 to 0.62$)$ & \\
\hline \multicolumn{5}{|l|}{ Comorbid disease } \\
\hline Coronary artery disease & $1.13(1.00$ to 1.28$)$ & 0.05 & 0.95 (0.75 to 1.21$)$ & 0.70 \\
\hline Heart failure & $1.58(1.22$ to 2.04$)$ & $<0.001$ & $1.32(1.02$ to 1.74$)$ & 0.05 \\
\hline Cerebrovascular disease & $1.30(0.88$ to 1.91$)$ & 0.19 & $1.06(0.71$ to 1.58$)$ & 0.77 \\
\hline Peripheral vascular disease & $1.11(0.75$ to 1.65$)$ & 0.61 & 0.85 (0.57 to 1.27$)$ & 0.42 \\
\hline Diabetes & $1.27(1.12$ to 1.44$)$ & $<0.001$ & 1.15 (1.00 to 1.31$)$ & 0.04 \\
\hline Hypertension & 1.21 (1.06 to 1.38$)$ & 0.005 & $1.06(0.92$ to 1.23$)$ & 0.42 \\
\hline Pulmonary disease & 2.28 (1.77 to2.92) & $<0.001$ & $1.53(1.17$ to 1.99$)$ & 0.002 \\
\hline Renal disease & $1.22(0.90$ to 1.65$)$ & 0.20 & 1.01 (0.74 to 1.39$)$ & 0.94 \\
\hline \multicolumn{5}{|l|}{ Malignancy: } \\
\hline Primary & 1.15 (1.01 to 1.30$)$ & \multirow[t]{2}{*}{0.03} & $1.05(0.91$ to 1.21$)$ & \multirow[t]{2}{*}{0.21} \\
\hline Metastatic & $1.93(1.22$ to 3.05$)$ & & $1.41(0.88$ to 2.25$)$ & \\
\hline \multicolumn{5}{|l|}{ Preoperative drug use $†$} \\
\hline Benzodiazepines & $1.40(1.20$ to 1.64$)$ & $<0.001$ & $1.26(1.07$ to 1.48$)$ & 0.005 \\
\hline SSRIs & 1.55 (1.22 to 1.98$)$ & $<0.001$ & $1.41(1.10$ to 1.80$)$ & 0.01 \\
\hline$\beta$ blockers & $1.15(1.02$ to 1.30$)$ & 0.02 & $1.05(0.92$ to 1.21$)$ & 0.35 \\
\hline Statins & $1.17(1.04$ to 1.31$)$ & 0.01 & $1.00(0.88$ to 1.14$)$ & 0.75 \\
\hline ACE inhibitors & 1.34 (1.19 to 1.50$)$ & $<0.001$ & $1.26(1.09$ to 1.44$)$ & $<0.001$ \\
\hline
\end{tabular}


Table 3 (continued)

\begin{tabular}{lccc} 
& \multicolumn{2}{c}{ Unadjusted comparison } & \multicolumn{2}{c}{ Adjusted comparison } & Odd ratio (95\% $\mathbf{~ I})$ \\
\cline { 2 - 4 } Factors & Odds ratio $(95 \% \mathrm{Cl})$ & $\mathbf{P}$ value & $\mathbf{P}$ value \\
Angiotensin receptor blockers & $1.05(0.90$ to 1.24$)$ & 0.52 & $1.08(0.90$ to 1.28$)$ \\
\hline
\end{tabular}

$\mathrm{ACE}=$ angiotensin converting enzyme; $\mathrm{CABG}=$ coronary artery bypass graft; $\mathrm{NA}=$ not applicable; $\mathrm{SSR}$ s=selective serotonin reuptake inhibitors.

${ }^{*}$ Multivariable logistic regression model used for these analyses had good calibration (Hosmer-Lemeshow statistic $\left.P=0.59\right)$ and modest discrimination $(C$ statistic 0.64).

†Outpatient prescription within 90 days before index surgery. 